\title{
A novel approach to medical radioisotope production using inverse kinematics: a successful production test of the theranostic radionuclide ${ }^{67} \mathrm{Cu}$
}

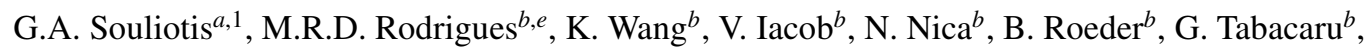 \\ M. Yu ${ }^{c}$, P. Zanotti-Fregonara ${ }^{c}$, A. Bonasera ${ }^{b, d}$ \\ ${ }^{a}$ Laboratory of Physical Chemistry, Department of Chemistry, National and Kapodistrian University of Athens, Athens 15771, Greece \\ ${ }^{b}$ Cyclotron Institute, Texas A $\mathcal{E}$ M University, College Station, Texas 77048, USA \\ ${ }^{c}$ Houston Methodist Research Institute, Houston, Texas, 77030, USA \\ ${ }^{d}$ Laboratori Nazionali del Sud, INFN, Catania 95123, Italy \\ e Instituto de Física, Universidade de São Paulo, São Paulo 05508-090, Brazil
}

\section{Abstract}

A novel method for the production of important medical radioisotopes has been developed. The approach is based on performing the nuclear reaction in inverse kinematics, namely sending a heavy-ion beam of appropriate energy on a light target (e.g. $\mathrm{H}, \mathrm{d}, \mathrm{He}$ ) and collecting the isotope of interest. In this work, as a proof-of-concept, we studied the production of the theranostic radionuclide ${ }_{1}^{67} \mathrm{Cu}\left(\mathrm{T}_{1 / 2}=62 \mathrm{~h}\right)$ via the reaction of a ${ }^{70} \mathrm{Zn}$ beam at $15 \mathrm{MeV} /$ nucleon with a hydrogen gas target. The ${ }^{67} \mathrm{Cu}$ radionuclide, alongside other coproduced isotopes, was collected after the gas target on an $\mathrm{Al}$ catcher foil and their radioactivity was measured by offline $\gamma$-ray analysis. After $36 \mathrm{~h}$ from the end of the irradiation, apart from the product of interest ${ }^{67} \mathrm{Cu}$, the main radioimpurity coming from the ${ }^{70} \mathrm{Zn}+\mathrm{p}$ reaction was ${ }^{69 m} \mathrm{Zn}\left(\mathrm{T}_{1 / 2}=13.8 \mathrm{~h}\right)$ that can be reduced by further radio-cooling. Moreover, along with the radionuclide of interest produced in inverse kinematics, the production of additional radioisotopes is possible by making use of the forward-focused neutrons from the reaction and letting them interact with a secondary target. A preliminary successful test of this concept was realized in the present study. The main requirement to obtain activities appropriate for preclinical studies is the development of high-intensity heavy-ion primary beams.

'Keywords:

\section{Introduction}

Medical radionuclides play a central role in nuclear medicine in the fields of diagnostic imaging and radioimmunotherapy (RIT) (Qaim (2017); Srivastava (2014); Stocklin (1995)). Radionuclides emitting low-range highly ionizing radiation $\left(\beta^{-}\right.$or $\alpha$ particles, Auger or conversion electrons) are essential for RIT approaches. Apart from a number of standard radionuclides, currently the $\beta^{-}$emitters ${ }^{47} \mathrm{Sc}\left(\mathrm{T}_{1 / 2}=3.4 \mathrm{~d}\right),{ }^{67} \mathrm{Cu}\left(\mathrm{T}_{1 / 2}=2.6 \mathrm{~d}\right)$, ${ }^{105} \mathrm{Rh}\left(\mathrm{T}_{1 / 2}=1.5 \mathrm{~d}\right),{ }^{161} \mathrm{~Tb}\left(\mathrm{~T}_{1 / 2}=6.9 \mathrm{~d}\right)$ and ${ }^{186} \operatorname{Re}\left(\mathrm{T}_{1 / 2}=3.7 \mathrm{~d}\right)$ (Champion (2016); Oaim (2017)) are increasingly interesting.

Specifically, ${ }^{67} \mathrm{Cu}$, the longest-lived radioisotope of copper, is ideally suited for both radioimmunotherapy and imaging for several reasons (Asabella (2014)). First, from a chemical perspective, copper is an essential trace element for most organisms and specifically for humans as it takes part in important biochemical processes (Linder (1991)). The coordination chemistry of $\mathrm{Cu}$ has been well established (Price (2014)). Copper can be linked to antibodies, proteins and other biologically important molecules (Follacchio (2018); Ting (2009); Schubiger (1996); Sugo (2017)). The nuclide ${ }^{67} \mathrm{Cu}$ can be

\footnotetext{
${ }^{1}$ Corresponding author: soulioti@ chem.uoa.gr
}

combined with the same type of radiopharmaceuticals as ${ }^{64} \mathrm{Cu}$ $\left(\mathrm{T}_{1 / 2}=12.7 \mathrm{~h}\right)$ or ${ }^{61} \mathrm{Cu}\left(\mathrm{T}_{1 / 2}=3.3 \mathrm{~h}\right)$ leading to efficient theranostic pairs (Zimmerman (2003)).

The half-life of ${ }^{67} \mathrm{Cu}(62 \mathrm{~h})$ is appropriate to deliver a high dose rate to the tumor. Furthermore, its $\beta^{-}$decay $\left(\mathrm{E}_{e, \text { ave }}=\right.$ $141 \mathrm{keV})$ is followed by the emission of soft $\gamma$ radiation of $185 \mathrm{keV}(48.7 \%), 93 \mathrm{keV}(16 \%)$ and $91 \mathrm{keV}(7 \%)$. This makes ${ }^{67} \mathrm{Cu}$ suitable for imaging the radiotracer distribution by single-photon emission computed tomography (SPECT) using the cameras widely developed for the $140 \mathrm{keV} \gamma$ rays of ${ }^{99 m} \mathrm{Tc}$. Compared to the standard RIT radioisotope ${ }^{90} \mathrm{Y}\left(\mathrm{T}_{1 / 2}=64 \mathrm{~h}\right.$, $\mathrm{E}_{e, \text { max }}=2.28 \mathrm{MeV}$ ), which is a pure $\beta^{-}$emitter, ${ }^{67} \mathrm{Cu}$ offers the possibility of SPECT imaging and treatment of smaller size tumors (up to $4 \mathrm{~mm}$, compared to $12 \mathrm{~mm}$ in the case of ${ }^{90} \mathrm{Y}$ ). In addition, ${ }^{67} \mathrm{Cu}$ compares favorably with another standard radioisotope, ${ }^{131} \mathrm{I}\left(\mathrm{T}_{1 / 2}=8.0 \mathrm{~d}, \mathrm{E}_{e, \text { max }}=0.61 \mathrm{MeV}\right)$, which has a longer half-life and emits higher energy $\gamma$ rays $(0.364 \mathrm{MeV}$, $82 \%$ ) and thus, may increase the undesired dose to the patient and the medical personnel.

It is noteworthy that while the other radioisotopes of copper, especially ${ }^{64} \mathrm{Cu}$, have already been used in radiopharmaceuticals for a wide range of preclinical and clinical studies (Follacchio (2018); Peng (2006)), ${ }^{67} \mathrm{Cu}$ has been used in a rather 
limited number of studies, albeit with very promising results (Jin (2017); Katz (1990); Knogler (2007); Novak (2002)). The main factor limiting the wider preclinical and clinical use is its limited availability (Smith (2012)).

The production of ${ }^{67} \mathrm{Cu}$ in nuclear reactors started about 50 years ago (O’Brien (1969)) and continues until present in several reactor facilities (e.g. Johnsen (2015); Uddin (2014); Mirzadeh (1986)). Recently, however, the main focus has shifted to methods based on particle accelerators (Smith (2012)). Presently, the main production route is via the reaction ${ }^{68} \mathrm{Zn}(\mathrm{p}, 2 \mathrm{p}){ }^{67} \mathrm{Cu}$ (Katabuchi (2008); Medvedev (2008); Pupillo (2018); Stoll (2002)). This approach is based on the use of intense medium-energy $\left(\mathrm{E}_{p}=70-100 \mathrm{MeV}\right)$ proton beams that are available by several particle accelerators, including mediumenergy cyclotrons. However, these multipurpose facilities cannot dedicate all their beam time to radioisotope production.

Other production routes based on lower-energy charged particle reactions are ${ }^{70} \mathrm{Zn}(\mathrm{p}, \alpha){ }^{67} \mathrm{Cu}$ (Hilgers (2003); Jamriska (1995); Kastleiner (1999)), ${ }^{70} \mathrm{Zn}(\mathrm{d}, \alpha \mathrm{n}){ }^{67} \mathrm{Cu}$ (Kozempel (2012)) and ${ }^{n a t} \mathrm{Zn}(\mathrm{d}, \mathrm{x}){ }^{67} \mathrm{Cu}$ (Hosseini (2017)), ${ }^{64} \mathrm{Ni}(\alpha, \mathrm{p}){ }^{67} \mathrm{Cu}$ (Ohya (2018); Skakun (2004)). Moreover, production routes based on reactions induced by accelerator-produced neutrons have been applied (Kawabata (2015); Kin (2013); Sato (2014); Spahn (2004)). In addition, ${ }^{67} \mathrm{Cu}$ has been produced in photonuclear reactions using bremsstrahlung photons from highintensity electron linacs (Gopalakrishna (2018); Starovoitova (2014, 2015); Yagi (1978)).

Finally, isotope harvesting in projectile fragmentation facilities has been suggested as an alternative source of medical isotopes. A proof-of-concept was presented in the recent work by Mastren et al. (Mastren (2014, 2015)) at the NSCL. This work involved harvesting and separation of ${ }^{67} \mathrm{Cu}$ from a mixture of projectile fragments stopped in an aqueous beam-collection system. The ${ }^{67} \mathrm{Cu}$ radionuclide separation was followed by radiolabelling and biodistribution studies.

A general characteristic of all the previous production methods is the fact that the desired radioisotope of ${ }^{67} \mathrm{Cu}$ is produced inside the target material which can be moderately or highly expensive, depending on the setup and approach. In regard to the production of ${ }^{67} \mathrm{Cu}$, the natural abundance of ${ }^{68} \mathrm{Zn}$ is $18.45 \%$, ${ }^{70} \mathrm{Zn}$ is $0.61 \%$ and ${ }^{64} \mathrm{Ni}$ is $0.93 \%$. Thus, in these cases, an efficient analysis scheme is necessary for the collection of the desired ${ }^{67} \mathrm{Cu}$ isotope and the recovery of the target material for subsequent re-use in the production scheme (Smith (2012)).

Along with this traditional scheme, in the isotope-harvesting route, the isotope of interest has to be separated from a very broad range of radioisotopes of other elements that are abundantly coproduced in a projectile fragmentation reaction. Thus, an appropriate multistep separation process is necessary (Mastren (2015)).

In this paper, we present an innovative approach for the production of medical radioisotopes based on inverse-kinematics nuclear reactions, that is, sending a heavy-ion beam on a light target and collecting the radioisotope after the target. The main advantage of using an inverse kinematics reaction is that the products are strongly focused along the beam direction and, thus, can be easily collected for immediate use.
Proof-of-principle of the aforementioned approach is presented for the production of ${ }^{67} \mathrm{Cu}$ via the reaction of a ${ }^{70} \mathrm{Zn}$ beam at $15 \mathrm{MeV} /$ nucleon with a hydrogen gas target. This work demonstrates that important non-standard medical radioisotopes with high radionuclide purity can be produced, provided that low-energy and high-intensity primary beams are available. Our method has some similarity with the isotope-harvesting approach from fragmentation facilities, in the sense that, in the latter, the fragmentation reactions also occur in inverse kinematics, albeit at high energies (above $100 \mathrm{MeV} /$ nucleon) producing a very broad range of isotopes. The inverse kinematics approach, however, takes place at low energy. By choosing the appropriate reaction channel, the radionuclide of interest can be selectively produced with minimal radioimpurities and implanted in an appropriate catcher material for subsequent use (after minimal radiochemical processing if necessary). In parallel, the forward-focused neutrons from the primary reaction can be sent to a secondary target for additional radioisotope production.

The structure of the paper is as follows: in section 2, we present the experimental setup and the measurements; in section 3, we continue with the data analysis and the results. In section 4, we discuss improvements of the present method and further plans. Finally, in section 5, we provide a summary and conclusions.

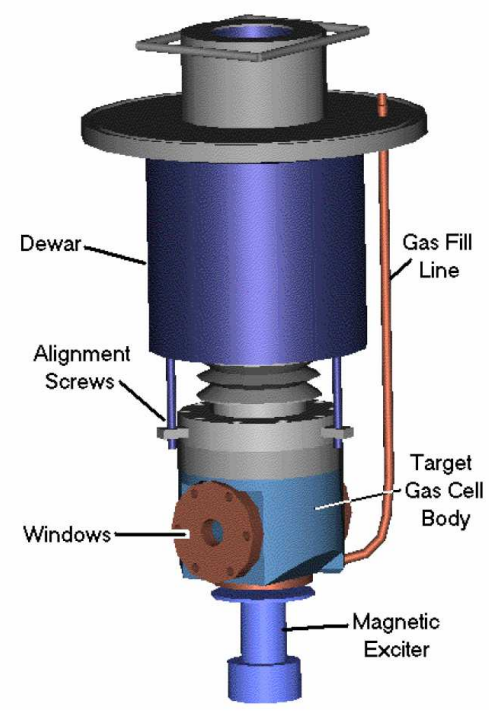

Figure 1: (Color online) The cryogenic gas target cell used in the present work (Brinkley (2003)).

\section{Experimental Setup and Measurements}

The experimental work took place at the Cyclotron Institute of Texas A\&M University (TAMU). A primary beam of ${ }^{70} \mathrm{Zn}^{15+}$ from the ECR source was accelerated by the K500 superconducting cyclotron to an energy of $15 \mathrm{MeV} /$ nucleon and transported to the target chamber of the MARS recoil separator 


\section{Irradiation setup for ${ }^{67} \mathrm{Cu}$ production in inverse kinematics}

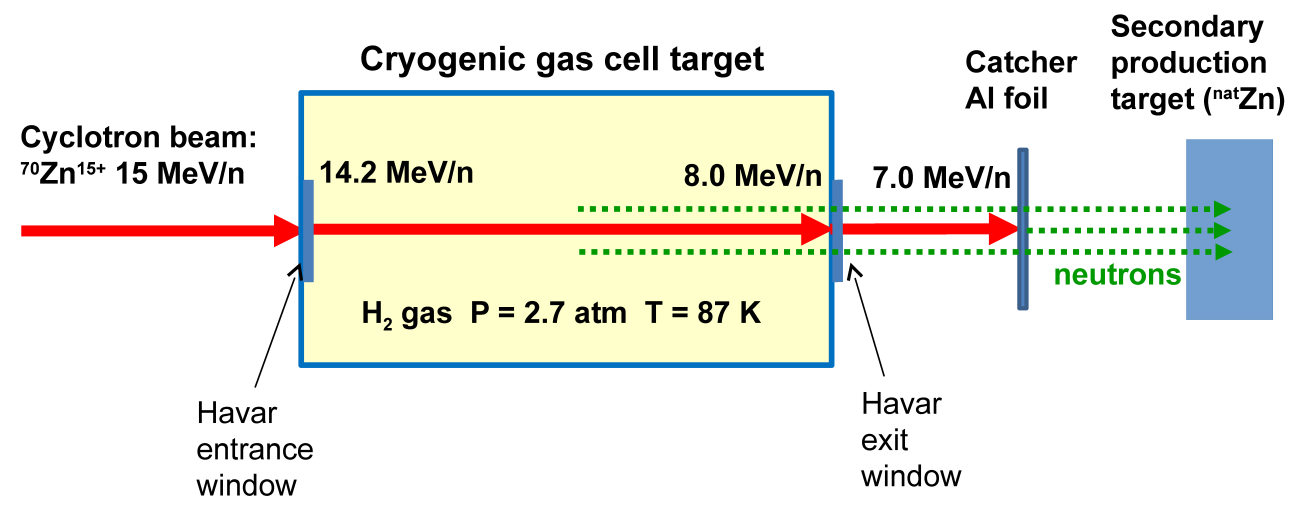

Figure 2: (Color online) Schematic diagram of the irradiation setup. A ${ }^{70} \mathrm{Zn}$ beam at $15 \mathrm{MeV} /$ nucleon enters the gas cell and interacts with the hydrogen gas. The heavy reaction products, including ${ }^{67} \mathrm{Cu}$, after exiting the gas cell are implanted in the $\mathrm{Al}$ catcher. The energies of the beam are listed as it passes through the entrance window, the gas and the exit window (thick red arrows). The dashed (green) arrows represent the neutrons produced via the interactions of the ${ }^{70} \mathrm{Zn}$ beam with the hydrogen gas and the Al catcher. For details, see sections 2, 3.2 and 3.3.

(Tribble (1989)). The beam impinged on a cryogenic gas cell filled with $\mathrm{H}_{2}$ gas held at a pressure of $2.7 \mathrm{~atm}$ in contact with a liquid nitrogen reservoir (Brinkley (2003)). The cryogenic gas cell (figure 1) has a length of $10 \mathrm{~cm}$ with $4 \mu \mathrm{m}$ Havar entrance and exit windows of $19.0 \mathrm{~mm}$ diameter. The experimental setup is schematically shown in figure 2 . An aluminum foil, mounted on an aluminum target frame (with a hole of $12.7 \mathrm{~mm}$ ) placed after the hydrogen gas cell, was used to collect the produced ${ }^{67} \mathrm{Cu}$ nuclei from the reaction of the ${ }^{70} \mathrm{Zn}$ beam with the proton target. The irradiation lasted $6.5 \mathrm{~h}$ with a beam current of 0.31 pnA (particle nA) $\left(2.0 \times 10^{9}\right.$ particles s $\left.^{-1}\right)$. The current was periodically monitored and was nearly constant (within $15 \%$ ). The measurement of the current was performed by inserting a Faraday cup mounted on the same target ladder as the Al catcher frame. The measurement of the beam current at this location (i.e. after the gas cell) was $8.0 \mathrm{nA}$ of ${ }^{70} \mathrm{Zn}(7.0 \mathrm{MeV} /$ nucleon) at an average charge state of $26+$. This equilibrium charge state value was calculated with the parametrization of Leon et al. (Leon (1998)). After $36.4 \mathrm{~h}$ from the end of the irradiation, the $\mathrm{Al}$ catcher foil was moved in front of a high-purity germanium (HPGe) detector for off-line $\gamma$-ray analysis as described in the following sections.

\section{Data analysis and results}

\subsection{Off-line $\gamma$-ray analysis}

The radioactivity of the produced ${ }^{67} \mathrm{Cu}$ and the other coproduced radioisotopes was determined by off-line analysis of the $\gamma$-ray spectra. The foil was placed at a distance of $d=17.2(10)$ $\mathrm{mm}$ from the end cap of the detector. Under this condition, the dead time of the counting system was around 2-3\%, thus avoiding the pile-up effect. The energy resolution of the detector system was 2.5-4.0 keV FWHM.

The energy calibration was performed using known $\gamma$-rays obtained in the spectra. The absolute efficiencies were obtained using photopeak efficiency predictions generated from a Geant 4
Agostinelli (2003)) simulation, considering the source and the detector geometry. The spectrum of the room background was measured for $67.3 \mathrm{~h}$.

The radioactivity levels of the isotopes were determined by the quantification of the photopeaks of the $\gamma$-rays taking into account the branching ratios and the absolute efficiencies of the detector. A detailed description of the $\gamma$-ray analysis of all the observed $\gamma$-ray peaks will be presented in Rodrigues (2019).

In figure 3, we present the background-subtracted $\gamma$-ray spectrum obtained during an accumulation period of $68.0 \mathrm{~h}$, starting $36.4 \mathrm{~h}$ after the end of the irradiation. We note that the peaks at $92 \mathrm{keV}$ and $185 \mathrm{keV}$ are characteristic of ${ }^{67} \mathrm{Cu}$ decay. The peak at $439 \mathrm{keV}$ is due to the main radioimpurity of ${ }^{69 m} \mathrm{Zn}\left(\mathrm{T}_{1 / 2}\right.$ $=13.8 \mathrm{~h}$ ) from the ${ }^{70} \mathrm{Zn}+\mathrm{p}$ reaction. We observe a small contribution, around $3 \%$ of the ${ }^{67} \mathrm{Cu}$ production, from $\gamma$-ray at 300.2 $\mathrm{keV}$ characteristic of the presence and decay of ${ }^{67} \mathrm{Ga}\left(\mathrm{T}_{1 / 2}=78\right.$ h) with a branching ratio of $16.7 \%$. We note that this radioimpurity, decaying to the same levels of ${ }^{67} \mathrm{Zn}$ as ${ }^{67} \mathrm{Cu}$, is intensely coproduced in the main production route via ${ }^{68} \mathrm{Zn}(\mathrm{p}, 2 \mathrm{p}){ }^{67} \mathrm{Cu}$ with high energy protons (Smith (2012)). This $\gamma$-ray for ${ }^{67} \mathrm{Cu}$ has a branching ratio of only $0.8 \%$. Similarly, the peak at $1115.5 \mathrm{keV}$, characteristic of ${ }^{65} \mathrm{Zn}\left(\mathrm{T}_{1 / 2}=244 \mathrm{~d}\right)$, is significantly suppressed ( $0.2 \%$ of the ${ }^{67} \mathrm{Cu}$ production). This radionuclide is notoriously produced in the high-energy ${ }^{67} \mathrm{Cu}$ production methods and requires radiochemical separation.

In the spectrum of figure 3, we observe peaks from a series of radionuclides that are mainly due to nuclear reactions on the Havar windows and the Al catcher foil. More specifically, the radionuclides ${ }^{86} \mathrm{Y},{ }^{87} \mathrm{Y},{ }^{89} \mathrm{Zr},{ }^{90} \mathrm{Nb}$ and ${ }^{93 m} \mathrm{Mo}$ are fusionevaporation products of the reaction ${ }^{70} \mathrm{Zn}+{ }^{27} \mathrm{Al}$ (with the beam of ${ }^{70} \mathrm{Zn}$ entering the $\mathrm{Al}$ catcher at $7.0 \mathrm{MeV} /$ nucleon, see section 3.2). Furthermore, the heavier radionuclides ${ }^{111} \mathrm{In},{ }^{117 m} \mathrm{Sn}$ and ${ }^{119} \mathrm{Te}$ are residues of the reaction of the ${ }^{70} \mathrm{Zn}$ beam with the constituents of the Havar alloy $(42 \% \mathrm{Co})$ of the gas-cell windows. We also identified the presence of ${ }^{7} \mathrm{Be}\left(\mathrm{T}_{1 / 2}=53 \mathrm{~d}, \mathrm{E}_{\gamma}=477.6\right.$ $\mathrm{keV}$ ) possibly coming from the activation of the small $\mathrm{Be}$ or $\mathrm{C}$ 


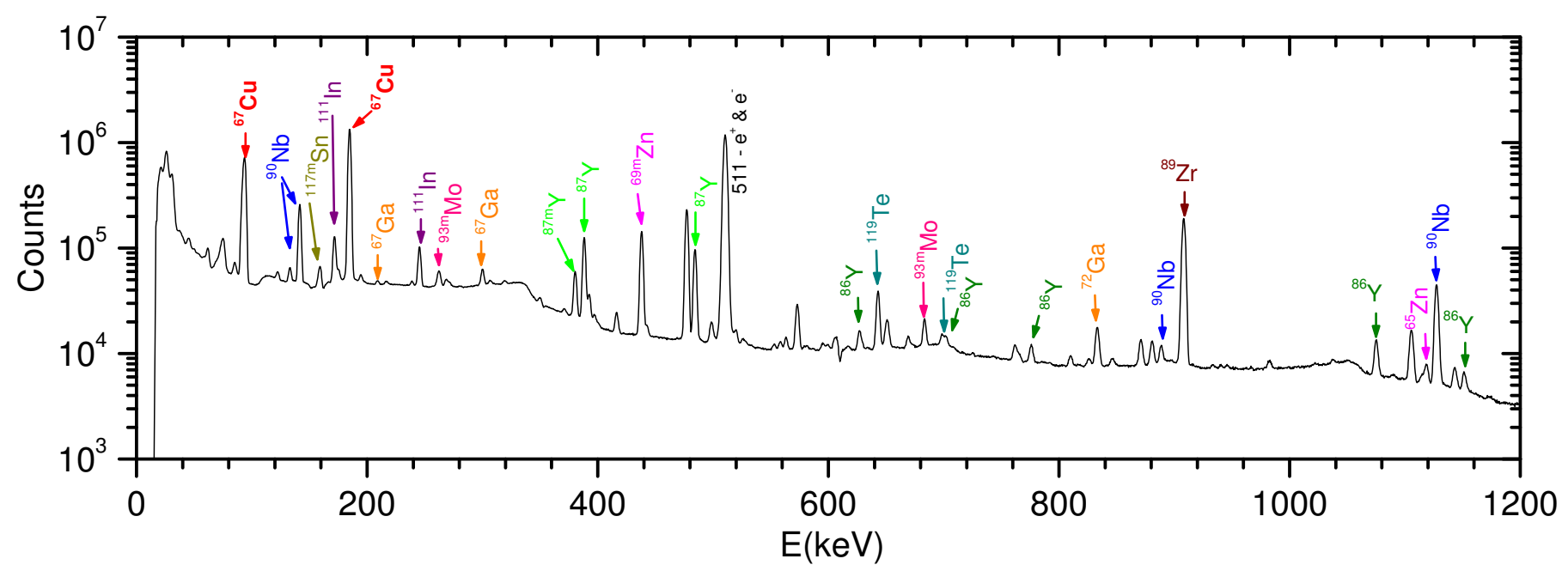

Figure 3: (Color online) Typical background-subtracted gamma-ray spectrum of the $\mathrm{Al}$ catcher foil following the interaction of a ${ }^{70} \mathrm{Zn}$ ( $15 \mathrm{MeV} / \mathrm{nucleon}$ ) beam with the hydrogen gas cell after $36.4 \mathrm{~h}$ from the end of the irradiation. The peaks are labelled with the corresponding radionuclides (see text). We specifically note the two peaks (at $92 \mathrm{keV}$ and $185 \mathrm{keV}$ ) due to ${ }^{67} \mathrm{Cu}$. and the peak (at $439 \mathrm{keV}$ ) due to ${ }^{69 m} \mathrm{Zn}\left(\mathrm{T}_{1 / 2}=13.8 \mathrm{~h}\right.$ ), which is the main radioimpurity coming from the production reaction ${ }^{70} \mathrm{Zn}+\mathrm{p}$.

content of the Havar alloy $(0.02-0.08 \%, 1.6 \%$, respectively). A complete analysis of the origin and the activity of these radionuclides will be presented in (Rodrigues (2019)). As we discuss in section 3.2, the radioimpurities coming from the Havar windows and the $\mathrm{Al}$ catcher can be easily reduced or completely eliminated by proper tuning of the energy loss of the primary beam in the gas cell, so they do not present a potential problem in the proposed method of radionuclide production.

From the above analysis, the activity of the produced ${ }^{67} \mathrm{Cu}$ at the end of the $6.5 \mathrm{~h}$ of irradiation was $1.6(5) \mathrm{kBq}$ with the beam current of $0.31 \mathrm{pnA}$. This leads to a specific activity of $0.8(3)$ $\mathrm{kBq} / \mathrm{h} / \mathrm{pnA}$ (or equivalently, 0.8(3) $\mathrm{MBq} / \mathrm{h} / \mathrm{p} \mu \mathrm{A}$ ).

Along with the activity of ${ }^{67} \mathrm{Cu}$, we report the measured activity of $0.094 \mathrm{kBq}$ of the ${ }^{69 m} \mathrm{Zn}\left(\mathrm{T}_{1 / 2}=13.8 \mathrm{~h}\right)$ at the end of the irradiation (this corresponds to a specific activity of 0.045 $\mathrm{kBq} / \mathrm{h} / \mathrm{pnA}$ ). This is a rather low activity that can be further reduced by an appropriate cooling period (of, e.g., 2 days).

\subsection{Comparison of measured ${ }^{67} \mathrm{Cu}$ activity with estimates}

In this section, we estimate the activity of the radionuclide ${ }^{67} \mathrm{Cu}$ produced in the inverse kinematics reaction ${ }^{70} \mathrm{Zn}$ (15 $\mathrm{MeV} /$ nucleon $)+\mathrm{p}$. The cross sections for the direct kinematics reaction ${ }^{70} \mathrm{Zn}(\mathrm{p}, \alpha){ }^{67} \mathrm{Cu}$ have been reported in Kastleiner (1999). We take into account that the $10 \mathrm{~cm}$ long gas target cell was filled with $\mathrm{H}_{2}$ gas at a pressure of 2.7 atm and was at a temperature of $87 \mathrm{~K}$ via the thermal contact with the $\mathrm{LN}_{2}$ Dewar. Under these conditions, the $\mathrm{H}_{2}$ gas target thickness was $7.5 \mathrm{mg} / \mathrm{cm}^{2}$. Using the code SRIM (Ziegler (2013)), we calculated the energy losses of the beam in the entrance window, the gas and the exit window of the gas cell. The ${ }^{70} \mathrm{Zn}$ beam hit the entrance window at $15 \mathrm{MeV} /$ nucleon, exited it at 14.2 $\mathrm{MeV} /$ nucleon, traversed the gas and reached the exit window at $8.0 \mathrm{MeV} /$ nucleon and, finally exited it at 7.0 MeV/nucleon (figure 2).

Using the data of Kastleiner et al. (Kastleiner (1999)), we estimated the integral of the excitation function in the region 14.2-8.0 MeV, resulting in an average value for the cross section of $7.5 \mathrm{mb}$ for ${ }^{67} \mathrm{Cu}$. Using this cross section value and the $\mathrm{H}_{2}$ gas target thickness, we obtained the production rate of ${ }^{67} \mathrm{Cu}$. Subsequently, we obtained the produced activity, assuming $1 \mathrm{~h}$ of irradiation with a beam intensity of $1 \mathrm{pnA}$. This activity is calculated to be $1.8 \mathrm{kBq} / \mathrm{h} / \mathrm{pnA}$ (or equivalently, 1.8 $\mathrm{MBq} / \mathrm{h} / \mathrm{p} \mu \mathrm{A})$. We notice that the measured activity of $0.8(3)$ $\mathrm{kBq} / \mathrm{h} / \mathrm{pnA}$ is about 2.2 times lower that the expected activity, as obtained with the procedure described above.

In this section, we discuss several possible sources for the discrepancy between the experimental and the theoretical activity of ${ }^{67} \mathrm{Cu}$ : a) the spread of the recoiling ${ }^{67} \mathrm{Cu}$ nuclei that may result in an incomplete collection on the $\mathrm{Al}$ catcher foil. As previously mentioned, the $\mathrm{Al}$ foil was mounted on an $\mathrm{Al}$ frame with a $12.7 \mathrm{~mm}$ hole. The ${ }^{67} \mathrm{Cu}$ activity of the target frame was measured to be $0.12 \mathrm{kBq}$ which is $7.5 \%$ of the main activity collected on the Al catcher foil; b) the use of an unsuppressed Faraday cup to measure the beam current. As it is well known, the sputtering of electrons from the side of the Faraday cup hit by the heavy-ion beam results in an increase of the measured positive current leading to a lowering of the obtained production rate and, thus, the specific activity. The cup should be biased to a positive voltage (in the range 200-400V). Such electron suppression of the Faraday cup was not performed in the present experiment. This effect may account for about $20-30 \%$ of the discrepancy, but it should be quantified for the present heavy-ion setup (as performed in Carzaniga (2017), figure 4, for proton beams); c) the reduction of the pressure of the $\mathrm{H}_{2}$ gas due to local heating along the path of the primary beam. As 
reported in a previous study (Brinkley (2003)), this effect has been observed in the behavior of this gas cell during its use for radioactive beam production with the MARS recoil separator. The rate of radioactive beams has been observed to drop when intense primary beams were used, but no quantitative estimates have been reported. A related quantitative account of this effect is reported by Amadio et al. (Amadio (2008)) for the production of a low-energy radioactive beam of ${ }^{7} \mathrm{Be}$ in a cryogenic hydrogen gas cell. In that setup, circulation of the hydrogen gas cooled at $\mathrm{LN}_{2}$ temperature indicated that the effect of the local pressure reduction may amount to $60-70 \%$ at high primary beam currents [figure 4 of (Amadio (2008))]. Similar measurements are necessary for the present gas cell. We note that a magnetic stirring system was operated in this cell, but its effect was rather inadequate.

Finally, we mention that, by using the cross section data of (Kastleiner (1999)), the production cross section of ${ }^{67} \mathrm{Cu}$ drops to nearly zero at about $7 \mathrm{MeV}$. Thus, in the energy range 14.2$8.0 \mathrm{MeV} /$ nucleon of the ${ }^{70} \mathrm{Zn}$ beam in the hydrogen gas, almost the full thickness of the target was exploited to produce ${ }^{67} \mathrm{Cu}$.

\subsection{Use of the neutrons from the primary reaction for sec- ondary radioisotope production}

The interaction of ${ }^{70} \mathrm{Zn}$ at $15 \mathrm{MeV} /$ nucleon with the proton target produces about 1.6 neutrons per reaction, as calculated with the code TALYS (Koning (2012); Duchemin (2015)). Along with the heavy reaction products, these neutrons are also kinematically focused in the forward direction and can be exploited for further radioisotope production by simply letting them interact with a secondary target, e.g., a ${ }^{68} \mathrm{Zn}$ or ${ }^{\text {nat }} \mathrm{Zn}$ target for additional production of ${ }^{67} \mathrm{Cu}$. In this work, we performed such a test by placing a block of twenty $25.4 \times 25.4 \mathrm{~mm}^{2}$ foils of ${ }^{n a t} \mathrm{Zn}$ with $1 \mathrm{~mm}$ thickness behind the $\mathrm{Al}$ catcher (figure 2).

Because this production is from the secondary neutrons, the yield is expected to be about 2 orders of magnitude lower than the main production channel. However, given the long mean free path of the neutrons (with a typical value of several $\mathrm{cm}$ ), production of different isotopes is conceivable with these neutrons impinging on different targets. This production scheme shares some similarity with the one recently published in (Auditore (2017)) employing secondary neutrons from the target of a standard ${ }^{18} \mathrm{~F}$ radioisotope-producing setup. The advantage of our approach of inverse kinematics is the strong focusing of the secondary neutrons that can be directed to a target stack of much smaller size than the one used in Auditore (2017)), which essentially encloses the target. The results of our neutron-production test are promising. The analysis work is currently in progress and will be presented in Rodrigues (2019).

\section{Discussion and plans}

The present preliminary study that we performed at the Cyclotron Institute of TAMU confirms that important medical radionuclides, such as ${ }^{67} \mathrm{Cu}$, can be effectively produced using inverse kinematics. The main advantages of the present novel approach along with necessary developments and relevant implementations are discussed below.
First, the produced radionuclides are strongly focused along the beam direction and, thus, can be easily collected. In this respect, with the appropriate choice of the reaction channel(s) and the subsequent cooling time of the products, it is possible to minimize the production of radioimpurities coming from the main reaction. Moreover, it is possible to minimize the radioimpurities resulting from the primary beam interacting with the Havar windows of the gas target and the catcher material. Of course, we cannot avoid reactions at the entrance window, where the beam enters with the full energy of $15 \mathrm{MeV} /$ nucleon and induces reactions on the foil. However, the products coming from peripheral or semiperipheral (deep-inelastic) collisions on the isotopes of Havar ( $\mathrm{Co}, \mathrm{Cr}, \mathrm{Ni}, \mathrm{W}$, etc.) have rather wide angular distributions [e.g., (Fountas (2014)) and (Papageorgiou (2018)) figure 4] and are expected to mostly miss the catcher (depending on its diameter). On the other hand, the products of complete or nearly complete fusion are forward focused, but are heavier and slower than the beam and, thus, may mostly stop in the gas.

Regarding the exit window, it is possible to adjust the gas cell parameters (pressure, temperature and length) so that the primary beam reaches this window at low energy, i.e. near or below the Coulomb barrier of the relevant reactions (e.g., 4.0 $\mathrm{MeV} /$ nucleon). Consequently, nuclear reactions can be suppressed or fully eliminated on that window. Of course, under these conditions, the low energy primary beam exiting the gas cell will not induce reactions in the catcher material. For example, referring to the ${ }^{70} \mathrm{Zn}+{ }^{27} \mathrm{Al}$ reaction, the Coulomb barrier corresponds to a projectile energy of $3.5 \mathrm{MeV} /$ nucleon. We realize that detailed simulations and further experimental tests are necessary to achieve optimum conditions for the experimental setup and production procedure. Under properly fine-tuned conditions, water or other materials (salt, sugar, etc.) can be used to collect the radioisotopes in a convenient chemical form, so that, post radiolabelling, they may be used for tests on animals.

As we briefly mentioned, secondary neutrons from the primary reaction can be used to irradiate other targets for further radioisotope production of the same or different type (e.g. $\mathrm{Cu}$, $\mathrm{Sc}$, etc.). However, in this case, radiochemical methods are needed to separate the medical radionuclides, as in the traditional production schemes (Smith (2012)).

From a financial point of view, material costs may be considerably reduced, since the heavy (and usually rare) element is used as the projectile (for instance, ${ }^{70} \mathrm{Zn}$ has $0.6 \%$ natural abundance). Also, the radiochemical processing is substantially minimized or, desirably, completely eliminated because the radioisotope of interest is collected and essentially used directly after production (and appropriate cooling). However, the primary requirement of our approach is the use of a heavy-ion accelerator (e.g., cyclotron or LINAC) that can deliver high-intensity heavy-ion beams in the energy range 10-20 $\mathrm{MeV} /$ nucleon. Fortunately, such accelerators are available at a number of facilities worldwide and, with appropriate planning, a fraction of their beam time may be devoted to non-standard radionuclide production following our inverse-kinematics approach. 
According to our estimates, with a primary beam of 1 particle $\mu \mathrm{A}$, we can reach activities of $1.8 \mathrm{MBq} / \mathrm{h}$ and, thus, obtain milliCurie quantities of ${ }^{67} \mathrm{Cu}$ within $24 \mathrm{~h}$ of irradiation. The $\mathrm{p} \mu \mathrm{A}$ heavy-ion beam intensities are achievable with the current ion-source and accelerator technology.

We note that the use of the cryogenic gas cell has the additional advantage that its cooled windows can withstand the necessary high beam currents. Appropriate circulation of the cooled hydrogen gas will be necessary to mitigate the effect of the local denstity reduction. For safe operation of the gas cell under intense beam irradiation, even with thinner windows, we may consider lowering the pressure to 1.0-1.5 atm, increasing the length, and, furthermore, lowering the temperature below $\mathrm{LN}_{2}$ temperatures with the use of modern cryocoolers [e.g., a Gifford-McMahon refrigerator (Radebaugh (2009))].

Taking advantage of the development of thin liquids, it is conceivable to substitute the hydrogen gas cell by a liquid $\mathrm{H}_{2}$ cell with thin windows. The development of a liquid $\mathrm{H}_{2} / \mathrm{D}_{2}$ target with typical thickness of a few $\mathrm{mm}$ is reported in (Jaeckle (1994)). More recently, a liquid $\mathrm{H}_{2}$ target for fragmentation reactions has been reported in (Ryuto (2005)). This target was operated at temperatures about $20 \mathrm{~K}$, achieved with a GiffordMcMahon refrigerator. The cell had a length of $30 \mathrm{~mm}$ and a density of $200 \mathrm{mg} / \mathrm{cm}^{2}$. We propose the implementation of a similar system for the production of medical isotopes, but for this purpose the length has to be only $1-2 \mathrm{~mm}$ to achieve the required thickness of about $8-10 \mathrm{mg} / \mathrm{cm}^{2}$.

In the case of the Cyclotron Institute of TAMU, the facility houses two cyclotrons: a) the K150 cyclotron which, in principle, can produce high-intensity heavy-ion beams (up to around $\mathrm{Kr}$ ) with energies up to around 12-15 MeV/nucleon, suitable for the production of relatively large activities of radioisotopes and, b) the K500 cyclotron, employed in the present experiment, which can produce lower currents of heavy-ion beams (upto ${ }^{238} \mathrm{U}$ ) and in a broader energy range (up to 20$40 \mathrm{MeV} /$ nucleon depending on the isotope). We anticipate that both the K150 and the K500 cyclotrons may be successfully used for the development and production of a variety of non-standard radioisotopes at activities appropriate for medical studies on small animals. For this purpose, however, beams of 30-100 pnA have to be developed, which should be possible with a modest investment at the existing ion-source and accelerator infrastructures.

To summarize, the aforementioned considerations for the development of a viable route of medical radioisotope production in inverse kinematics are based, first, on the successful results of the present study and, second, on the current experience and developments on ion-source and accelerator technologies worldwide. We think that a fruitful application of our proposed method is acheivable with timely planning and allocation of relatively modest resources. Along with the other production approaches, the proposed route may contribute to a broad and diversified program of production and use of non-standard medical radionuclides.

\section{Conclusions}

An innovative method for the production of important medical radioisotopes was presented in this article. The approach is based on realizing the nuclear reaction in inverse kinematics by sending a heavy-ion beam of appropriate energy on a light target (e.g., H, d, He) and collecting the isotope of interest on an appropriate catcher after the target. In this work, as a proofof-principle, we studied the production of the radionuclide ${ }^{67} \mathrm{Cu}$ $\left(\mathrm{T}_{1 / 2}=62 \mathrm{~h}\right)$ via the reaction of a beam of $15 \mathrm{MeV} /$ nucleon ${ }^{70} \mathrm{Zn}$ with a cryogenic hydrogen gas target. The ${ }^{67} \mathrm{Cu}$ radionuclide (along with other coproduced isotopes) was collected after the gas target on an $\mathrm{Al}$ catcher foil and the radioactivity was measured by off-line $\gamma$-ray analysis. After the end of the irradiation, the main radioimpurity in the $\mathrm{Al}$ catcher coming from the ${ }^{70} \mathrm{Zn}+\mathrm{p}$ reaction was ${ }^{69 m} \mathrm{Zn}\left(\mathrm{T}_{1 / 2}=13.8 \mathrm{~h}\right)$, which can be suppressed by cooling for a period of 2-3 days. Other identified radioimpurities are understood to come from the interaction of the beam with the window material and the catcher and can be eliminated by careful tuning of the parameters of the setup. The present successful test and the ensuing considerations indicate the possibility of producing important non-standard radionuclides of high radionuclide purity with the approach of inverse kinematics. In parallel to the main production scheme, secondary neutrons from the primary reaction were used to irradiate a secondary target of $\mathrm{Zn}$ for further radioisotope production with promising results. The main requirement necessary to achieve production of activities appropriate for preclinical studies is the availability of high-intensity (particle $\mu \mathrm{A}$ ) heavy-ion primary beams.

\section{Acknowledgements}

We are grateful to the support staff of the Cyclotron Institute for providing the primary beam. We are thankful to Dr. H.T. Chifotides for inspiring discussions and suggestions on this collaborative work and for critical reading and editing of the manuscript. Financial support for this work was provided, in part by NNSA under grant no de-na0003841 (CENTAUR), and by the National and Kapodistrian University of Athens under the ELKE Research Account. MY and PZF acknowledge the support of Houston Methodist Research Institute (HMRI).

\section{References}

Agostinelli S., et al., 2003. Geant4 a simulation toolkit. Nucl. Instrum. Methods Phys. Res. A 506, 250-303.

Amadio G., Yamaguchi H., Wakabayashi Y., Hayakawa S., Kubono S., 2008. Development of a cryogenic gas target for intense RI beam production at CRIB. Nucl. Instrum. Methods Phys. Res. A 590, 191-193.

Asabella, A.N., Cascini, G.L., Altini, C., Paparella, D., Notaristefano, A., Rubini, G., 2014. The Copper Radioisotopes: A Systematic Review with Special Interest to ${ }^{64} \mathrm{Cu}$. BioMed Research International 2014, 786463.

Auditore, L., Amato, E., Baldari, S., 2017. Theoretical estimation of ${ }^{64} \mathrm{Cu}$ production with neutrons emitted during $18 \mathrm{~F}$ production with a $30 \mathrm{MeV}$ medical cyclotron. Appl. Radiat. Isot. 122, 229-234.

Brinkley, J.F., et al., 2009 Progress in Research, Cyclotron Institute, Texas AEM University (2002-2003), p. V-9 accessible at: http://cyclotron.tamu.edu/publications.html 
Carzaniga T.S., Auger M., Braccini S., Bunka M., Ereditato A., Nesteruk K.P. Scampoli P., Turler A., van der Meulen N., 2017. Measurement of ${ }^{43} \mathrm{Sc}$ and ${ }^{44} \mathrm{Sc}$ production cross section with an $18 \mathrm{MeV}$ medical PET cyclotron. Appl. Radiat. Isot. 129, 96-102.

Champion, C., Quinto, A.M., Morgatc C., Zanotti-Fregonara, P., Hindie, E., 2016. Comparison between Three Promising $\beta$-emitting Radionuclides, ${ }^{67} \mathrm{Cu},{ }^{47} \mathrm{Sc}$ and ${ }^{161} \mathrm{~Tb}$, with Emphasis on Doses Delivered to Minimal Residual Disease. Theranostics 6(4), 1611-1618.

Duchemin, C., Guertin, A., Haddad, F., Michel, N., Metivier, V., 2015. Production of medical isotopes from a thorium target irradiated by light charged particles up to $70 \mathrm{MeV}$. Phys. Med. Biol. 60, 931-946.

Follacchio, G.A., De Feo, M. S., De Vincentis, G., Monteleone F. , Liberatore M., 2018. Radiopharmaceuticals Labelled with Copper Radionuclides: Clinical Results in Human Beings. Current Radiopharmaceuticals 11(1), 22-33.

Fountas P.N., Souliotis G.A., Veselsky M., and Bonasera A., 2014. Systematic study of neutron-rich rare isotope production in peripheral heavy-ion collisions below the Fermi energy. Phys. Rev. C 90, 064613.

Gopalakrishna, A., Suryanarayana, S.V., Naik H., Dixit, T. S., Nayak, B.K., Kumar A., Maletha P., Thakur, K., Deshpande, A., Ramamoorthy Krishnan, R., Kamaldeep, Banerjee, S., Saxena, A., 2018. Production, separation and supply prospects of ${ }^{67} \mathrm{Cu}$ with the development of fast neutron sources and photonuclear technology. Radiochim. Acta 106(7), 549-557.

Hilgers, K., Stoll, T., Skakun, Y., Coenen, H.H., Qaim, S.M., 2003. Cross section measure ments of the nuclear reactions ${ }^{n a t} \mathrm{Zn}(\mathrm{d}, \mathrm{x}){ }^{64} \mathrm{Cu},{ }^{66} \mathrm{Zn}(\mathrm{d}, \alpha){ }^{64} \mathrm{Cu}$, ${ }^{68} \mathrm{Zn}(\mathrm{p}, \alpha \mathrm{n}){ }^{64} \mathrm{Cu}$ for production of ${ }^{64} \mathrm{Cu}$ and technical developments for small scale production of $67 \mathrm{Cu}$ via the ${ }^{70} \mathrm{Zn}(\mathrm{p}, \alpha){ }^{67} \mathrm{Cu}$ process. Appl. Radiat. Isot. 59, 343-351.

Hosseini, S.F., Aboudzadeh, M., Sadeghi, M., Ahmadi Teymourlouy, A., Rostampour M., 2017. Assessment and estimation of ${ }^{67} \mathrm{Cu}$ production yield via deuteron induced reactions on ${ }^{\text {nat }} \mathrm{Zn}$ and ${ }^{70} \mathrm{Zn}$. Appl. Radiat. Isot. 127, 137141.

Jaeckle V., Kilian K., Machner H., Nake Ch., Oelert W., Turek P., 1994. A liquid hydrogen/deuterium target with very thin windows Nucl. Instrum. Methods Phys. Res. A 349, 15-17.

Jamriska Sr., D.J., Taylor, W.A., Ott, M.A., Heaton, R., Phillips, D., Fowler, M., 1995. Activation rates and chemical recovery of ${ }^{67} \mathrm{Cu}$ produced with low energy proton irradiation of enriched ${ }^{67} \mathrm{Zn}$ targets. J. Radioanal. Nucl. Chem. 195, 263-270.

Jin, Z.H., Furukawa, T., Ohya, T., Degardin, M., Sugyo, A., Tsuji, A.B., Fujibayashi, Y., Zhang, M.R., Higashi, T., Boturyn, D., Dumy, P., Saga, T., 2017. ${ }^{67} \mathrm{Cu}$-Radiolabeling of a multimeric RGD peptide for $\alpha \mathrm{V} \beta 3$ integrintargeted radionuclide therapy: stability, therapeutic efficacy, and safety studies in mice. Nucl. Med. Commun. 38(4), 347-355.

Johnsen, A.M., Heidrich, B.J., Durrant, C.B., Bascom, A.J., Unlu, K., 2015 Reactor production of ${ }^{64} \mathrm{Cu}$ and ${ }^{67} \mathrm{Cu}$ using enriched zinc target material. J. Radioanal. Nucl. Chem. 305, 61 .

Kastleiner, S., Koenen, H.H., Qaim, S.M., 1999. Possibility of production of ${ }^{67} \mathrm{Cu}$ at a small-sized cyclotron via the $(\mathrm{p}, \alpha)$ reaction on enriched ${ }^{70} \mathrm{Zn}$. Radiochim. Acta 84, 107-110.

Katabuchi, T., Watanabe, S., Ishioka, N.S., Iida, Y., Hanaoka, H., Endo, K.., et al., 2008. Production of ${ }^{67} \mathrm{Cu}$ via the ${ }^{68} \mathrm{Zn}(\mathrm{p}, 2 \mathrm{p}){ }^{67} \mathrm{Cu}$ reaction and recovery of ${ }^{68} \mathrm{Zn}$ target. J. Radioanal. Nucl. Chem. 277, 467-70.

Katz, B.M., Barnea, A., 1990. The Ligand Specificity for Uptake of Complexed Copper-67 by Brain Hypothalamic Tissue Is a Function of Copper Concentration and Copper:Ligand Molar Ratio. J. Biol. Chem. 265, 2017-2021.

Kawabata, M., Hashimoto, K., Saeki, H., Sato, N., Motoishi, S., Nagai, Y., 2015. Production and separation of ${ }^{64} \mathrm{Cu}$ and ${ }^{67} \mathrm{Cu}$ using $14 \mathrm{MeV}$ neutrons. J. Radioanal. Nucl. Chem. 303, 1205.

Kin, T., Nagai, Y., Iwamoto, N., Minato, F., Iwamoto, O., Hatsukawa, Y., Segawa,M., Harada, H., Konno, C., Ochiai, K., Takakura, K., 2013. New production routes for medical isotopes ${ }^{64} \mathrm{Cu}$ and ${ }^{67} \mathrm{Cu}$ using accelerator neutrons. J. Phys. Soc. Japan 82, 034201.

Knogler, K., Grunberg, J., Zimmermann, K., Cohrs, S., Honer, M., Ametamey, S., Altevogt, P., Fogel, M., Schubiger, P.A., Novak-Hofer, I., 2007. Copper67 Radioimmunotherapy and Growth Inhibition by Anti L1-Cell Adhesion Molecule Monoclonal Antibodies in a Therapy Model of Ovarian Cancer Metastasis. Clin. Cancer Res. 13(2), 603-611.

Koning, A.J., Rochman, D., 2012. Modern nuclear data evaluation with the TALYS code system, Nucl. Data Sheets 113 (12) 28412934

Kozempel, J., Abbas, K., Simonelli, F., Bulgheroni, A., Holzwarth, U., Gibson, N., 2012. Preparation of ${ }^{67} \mathrm{Cu}$ via deuteron irradiation of ${ }^{70} \mathrm{Zn}$. Radiochim.
Acta 100, 419-423.

Leon A. et al., 1998. Charge state distributions of swift heavy ions behind various solid targets. At. Data Nucl. Data Tables 69, 217-238.

Linder, M.C., 1991. Biochemistry of Copper (Plenum Press, NY) 1st ed.

Mastren, T., Pen, A., Peaslee, G.F., Wozniak, N., Loveless, S., Essenmacher, S., Sobotka, L.G., Morrissey, D.J., Lapi, S.E., 2014. Feasibility of isotope harvesting at a projectile fragmentation facility: ${ }^{67} \mathrm{Cu}$. Sci. Rep. 4:6706, 1-6.

Mastren, T., Pen, A., Loveless, S., Marquez, B.V., Bollinger, E., Marois, B., Hubley, N., Brown, K., Morrissey, D.J., Peaslee, G.F., Lapi, S.E., 2015. Harvesting ${ }^{67} \mathrm{Cu}$ from the collection of a secondary beam cocktail at the National Superconducting Cyclotron Laboratory. Anal. Chem. 87(20), 1032329.

Medvedev, D.G., Mausner, L.F., Meinken, G.E., Kurczak, S.O., Schnakenberg, H., Dodge, C.J., et al., 2008. Development of a large scale production of ${ }^{67} \mathrm{Cu}$ from ${ }^{68} \mathrm{Zn}$ at the high energy proton accelerator: closing the ${ }^{68} \mathrm{Zn}$ cycle. Appl. Radiat. Isot. 70, 423-9.

Mirzadeh, S., Mausner, L. F., Srivastava, S.C., 1986. Production of no-carrier added ${ }^{67} \mathrm{Cu}$. Appl. Radiat. Isot. 37, 29 (1986).

Novak-Hofer, I., Schubiger, P.A., 2002. Copper-67 as a therapeutic nuclide for radioimmunotherapy. Eur J Nucl Med Mol Imaging 29(6), 821-30.

O'Brien, H.A., 1969. The Preparation of ${ }^{67} \mathrm{Cu}$ from ${ }^{67} \mathrm{Zn}$ in a Nuclear Reactor. Int. J. Appl. Radiat. Isot. 20, 121-124.

Ohya, T., Nagatsu, K., Suzuki, H., Fukada, M., Minegishi, K., Hanyu, M., Zhang, M.R., 2018. Small-scale production of ${ }^{67} \mathrm{Cu}$ for a preclinical study via the ${ }^{64} \mathrm{Ni}(\alpha, \mathrm{p}){ }^{67} \mathrm{Cu}$ channel. Nucl Med Biol. 59, 56-60.

Papageorgiou A., Souliotis G.A., K Tshoo K., Jeong S. C., Kang B.H., Kwon Y. K., Veselsky M., Yennello S.J., Bonasera A. Neutron-rich rare isotope production with stable and radioactive beams in the mass range $A=40-60$ at beam energy around $15 \mathrm{MeV} /$ nucleon. J. Phys. G, Nucl. Part. Phys. 45, 095105 (25pp).

Peng, F., Lu, X., Janisse, J., Muzik, O., Shields, A.F., 2006. PET of human prostate cancer xenografts in mice with increased uptake of ${ }^{64} \mathrm{CuCl}_{2}$. J. Nucl. Med. 47, 1649.

Price, E. W., Orvig, C., 2014. Matching chelators to radiometals for radiopharmaceuticals. Chem. Soc. Rev. 43, 260.

Pupillo, G., Sounalet, T., Michel, N., Mou, L., Esposito, J., Haddad, F., 2018. New production cross sections for the theranostic radionuclide ${ }^{67} \mathrm{Cu}$. Nucl. Inst. Methods Phys. Res. B 415, 41-47.

Qaim, S.M., 2017. Nuclear data for production and medical application of radionuclides: present status and future needs. Nucl. Med. Biol. 44, 31-49.

Radebaugh R., 2009. Cryocoolers: the state of the art and recent developments. J. Phys. Condens. Matter 21, 164219 (9pp).

Rodrigues, M.R.D., Souliotis, G.A., Wang K., Iakob, V., Nica, N., Roedder, B., Tabacaru, G., Yu, M., Zanotti-Fregonara, P., Bonasera, A., 2019. A novel dual approach to medical radioisotope production employing inverse kinematics and the secondary emitted neutrons. A successful test to produce the medical radionuclide ${ }^{67} \mathrm{Cu}$. NIMB in preparation.

Ryuto H., Kunibu M., Minemura T., Motobayashi T., Sagara K., Shimura S., Tamaki M., Yanagisawa Y., Yano Y. 2005. Liquid hydrogen and helium targets for radioisotope beams at RIKEN Nucl. Instrum. Methods Phys. Res. A $555,1-5$.

Sato, N., Tsukada, K., Watanabe, S., Ishioka, N. S., Kawabata, M., Saeki, H., Nagai, Y., Kin, T., Minato, F., Iwamoto, N., Iwamoto, O., 2014. First measurement of the radionuclide purity of the therapeutic isotope ${ }^{67} \mathrm{Cu}$ produced by ${ }^{\text {nat }} \mathrm{Zn}(\mathrm{n}, \mathrm{x})$ reaction using ${ }^{\text {nat }} \mathrm{C}(\mathrm{d}, \mathrm{n})$ neutrons. J. Phys. Soc. Japan 83, 073201.

Schubiger, P.A., Alberto, R., Smith, A., 1996. Vehicles, chelators and radionuclides: choosing the "building blocks" of an effective therapeutic radioimmunoconjugate. Bioconjugate Chem. 7, 165-179.

Skakun, Y., Qaim, S.M., 2004. Excitation function of the ${ }^{64} \mathrm{Ni}(\alpha, \mathrm{p})^{67} \mathrm{Cu}$ reaction for production of ${ }^{67} \mathrm{Cu}$, Appl. Radiat. Isot. 60, 33-39.

Smith N.A., Bowers D.L., Ehst D.A., 2012. The production, separation, and use of ${ }^{67} \mathrm{Cu}$ for radioimmunotherapy: a review. Appl. Radiat. Isot. 70, 2377 2383.

Spahn, I., Coenen, H.H., Qaim, S.M., 2004. Enhanced production possibility of the therapeutic radionuclides ${ }^{64} \mathrm{Cu},{ }^{67} \mathrm{Cu}$ and ${ }^{89} \mathrm{Sr}$ via (n, p) reactions induced by fast spectral neutrons. Radiochim. Acta 92, 183.

Srivastava, S.C., 2014. Paving the way to personalized medicine: production of some theragnostic radionuclides at Brookhaven National Laboratory. Radiochim. Acta 99, 635 .

Starovoitova, V.N., Tchelidze, L., Wells, D.P., 2014. Production of medical 
radioisotopes with linear accelerators. Appl. Radiat. Isot. 85, 39-44.

Starovoitova, V.N., Cole, P.L., Grimm, T.L., 2015. Accelerator-based photoproduction of promising beta-emitters ${ }^{67} \mathrm{Cu}$ and ${ }^{47} \mathrm{Sc}$. J. Radioanal. Nucl. Chem. 305 (1), 127-132.

Stocklin, G., Qaim, S.M., Rosch, F., 1995. The impact of radioactivity on medicine. Radiochim. Acta. 70/71, 249.

Stoll, T., Kastleiner, S., Shubin, Y.N, Coenen, H.H., Qaim, S.M., 2002. Excitation functions of proton induced reactions on ${ }^{68} \mathrm{Zn}$ from threshold up to $71 \mathrm{MeV}$, with specific reference to the production of ${ }^{67} \mathrm{Cu}$. Radiochim. Acta 90, 309-13.

Sugo, Y., Hashimoto, K., Kawabata, M., Saeki, H., Sato, S., Tsukada, K., Nagai, Y., 2017. Application of ${ }^{67} \mathrm{Cu}$ produced by ${ }^{68} \mathrm{Zn}(\mathrm{n}, \mathrm{np} ; \mathrm{d}){ }^{67} \mathrm{Cu}$ to biodistribution study in tumor-bearing mice. J. Phys. Soc. Japan. 86, 023201.

Ting, G., Chang, C.H., Wang, H.E., 2009. Cancer Nanotargeted Radiopharmaceuticals for Tumor Imaging and Therapy. Anticancer research 29, $4107-$ 4118.

Tribble, R.E., Burch, R.H., and Gagliardi C.A., 1989. MARS: A momentum achromat recoil spectrometer. Nucl. Instr. and Meth. A 285, 441-446.

Uddin, Md. S., Rumman-uz-Zaman, Md., Hossain, S.M., Qaim, S.M., 2014. Radiochemical measurement of neutron-spectrum averaged cross sections for the formation of ${ }^{64} \mathrm{Cu}$ and ${ }^{67} \mathrm{Cu}$ in the $(\mathrm{n}, \mathrm{p})$ reaction at a TRIGA MarkII reactor: Feasibility of simultaneous production of the theragnostic pair ${ }^{64} \mathrm{Cu} /{ }^{67} \mathrm{Cu}$ Radiochim. Acta. 102, 473.

Yagi, M., Kondo, K., 1978. Preparation of carrier-free ${ }^{67} \mathrm{Cu}$ by the ${ }^{68} \mathrm{Zn}(\gamma, \mathrm{p})$ reaction. Int. J. Appl. Radiat. Isot. 29, 757.

Ziegler, J.F., Ziegler, M.D., Biersack, J.P., 2013. The stopping and range of ions in matter. Available at: http://www.srim.org

Zimmermann, K., Grunberg, J., Honer, M., Ametamey, S., Schubiger, P.A., Novak-Hofer, I., 2003. Targeting of renal carcinoma with $67 / 64 \mathrm{Cu}$-labeled anti-L1-CAM antibody chCE7: selection of copper ligands and PET imaging. Nucl. Med. Biol. 30(4), 417-27. 